\title{
Overview of mitochondrial germline variants and mutations in human disease: Focus on breast cancer (Review)
}

\author{
SILVIA JIMÉNEZ-MORALES ${ }^{1}$, CARLOS J. PÉREZ-AMADO ${ }^{2}$, \\ ELIZABETH LANGLEY $^{3}$ and ALFREDO HIDALGO-MIRANDA ${ }^{1}$ \\ ${ }^{1}$ Laboratory of Cancer Genomics, National Institute of Genomic Medicine, 14610 Mexico City; \\ ${ }^{2}$ Biochemistry Sciences Program, National Autonomous University of Mexico, 04510 Mexico City; \\ ${ }^{3}$ Department of Basic Research, National Cancer Institute, 14080 Mexico City, Mexico
}

Received January 29, 2018; Accepted May 18, 2018

DOI: $10.3892 /$ ijo.2018.4468

\begin{abstract}
High lactate production in cells during growth under oxygen-rich conditions (aerobic glycolysis) is a hallmark of tumor cells, indicating the role of mitochondrial function in tumorigenesis. In fact, enhanced mitochondrial biogenesis and impaired quality control are frequently observed in cancer cells. Mitochondrial DNA (mtDNA) encodes 13 subunits of oxidative phosphorylation (OXPHOS), is present in thousands of copies per cell, and has a very high mutation rate. Mutations in mtDNA and nuclear DNA (nDNA) genes encoding proteins that are important players in mitochondrial biogenesis and function are involved in oncogenic processes. A wide range of germline mtDNA polymorphisms, as well as tumor mtDNA somatic mutations have been identified in diverse cancer types. Approximately $72 \%$ of supposed tumor-specific somatic mtDNA mutations reported, have also been found as polymorphisms in the general population. The ATPase 6 and $N A D H$ dehydrogenase subunit genes of mtDNA are the most commonly mutated genes in breast cancer (BC). Furthermore, nuclear genes playing a role in mitochondrial biogenesis and function, such as peroxisome proliferators-activated receptor gamma coactivator-1 (PGC-1), fumarate hydratase $(F H)$ and succinate dehydrogenase $(S D H)$ are frequently mutated in cancer. In this review, we provide an overview of the mitochondrial germline variants and mutations in cancer, with particular focus on those found in BC.
\end{abstract}

Correspondence to: Dr Silvia Jiménez-Morales or Dr Alfredo Hidalgo-Miranda, Laboratory of Cancer Genomics, National Institute of Genomic Medicine, Periférico Sur No. 4809, Col. Arenal Tepepan, Delegación Tlalpan, 14610 Mexico City, Mexico

E-mail: sjimenez@inmegen.gob.mx

E-mail: ahidalgo@inmegen.gob.mx

Abbreviations: mtDNA, mitochondria DNA; BC, breast cancer; OXPHOS, oxidative phosphorylation; NEMtG, nuclear-encoded mitochondrial genes

Key words: mitochondria DNA variants, mutations, breast cancer, haplogroups

\section{Contents}

1. Introduction

2. Mitochondria

3. Mitochondrial DNA variants in human diseases

4. Mitochondria variants and cancer

5. Mitochondrial DNA variants in breast cancer

6. Mitochondria DNA mutations and response to therapy in breast cancer

7. Conclusions

\section{Introduction}

Breast cancer (BC) is the most common epidermal neoplasia worldwide, representing approximately $12 \%$ of all new cancer cases and $25 \%$ of all cancer cases in women. Belgium has the highest rate of BC, followed by Denmark and France, while the lowest incidence has been observed in Asia and Africa (1). The Breast Cancer Organization estimates that approximately $12 \%$ of women from the United States will develop invasive $\mathrm{BC}$ during the course of their lifetime. Over the past decade, tremendous progress has been made in identifying BC etiological factors, understanding tumor biology, developing tools for better detection and determining the most effective treatments. Nevertheless, this disease still represents an important cause of morbi-mortality due to cancer $(1,2)$. It is widely known that the oncogenesis phenomenon is a complex biological mechanism not yet well understood. Cancer development is a multistep process, involving genome instability, which leads to sustained proliferative signaling, the evasion of growth suppressors, resistance to cell death, tumor angiogenesis, invasion and metastasis (3). Other hallmarks of the cancer cell are the capacity to evade the immune system and to generate reprogramming of the energy metabolism system $(4,5)$. As regards the latter hallmark, the most well-known tumor cell metabolic abnormality is the Warburg effect (4).

Otto Warburg observed that cancer cells prefer aerobic glycolysis to oxidative phosphorylation; however, these cells do not uptake oxygen like normal tissue cells, even under a normal oxygen environment $(4,6)$. Subsequently, there is ample evidence to support the hypothesis that tumor-related metabolic abnormalities involve defects in mitochondrial 
function, since many of the metabolic genes whose mutations can cause cancers are mitochondrial genes or nuclear encoded genes that are relevant to mitochondrial biogenesis and function. As an example, the metabolic enzyme, succinate dehydrogenase (SDH), is frequently mutated in cancer (7). In this review, we provide an overview of mitochondrial mutations and polymorphisms in cancer, emphasizing those in $\mathrm{BC}$.

\section{Mitochondria}

Mitochondria are involved in fundamental cellular processes, which include the generation of adenosine triphosphate (ATP) for cellular energy, calcium storage for cell signaling, and mediating cell growth and death processes. Mitochondria, descendants of endosymbiotic $\alpha$-protobacteria that become established in a host cell, are double-membraned and semi-autonomous organelles in eukaryotic cells that can autoreplicate and are maternally inherited. This organelle has its own genome and is organized into DNA-protein complexes termed mitochondrial nucleoids, which are relatively stable genetic elements. Human cells have approximately 2,000 mitochondria per cell and an average of between 1.4 and 7.5 mitochondrial DNA (mtDNA) molecules per nucleoid (8). mtDNA is a negatively supercoiled double-stranded circular molecule of 16,569 bp in size. Based on sedimentation properties, one strand is termed light $(\mathrm{L})$ and the other one heavy $(\mathrm{H})$. With only $<7 \%$ of the sequence considered non-coding, mtDNA contains 37 genes, 28 of which are encoded in the $\mathrm{H}$ strand and 9 in the $\mathrm{L}$ strand. Thirteen of these genes code for essential proteins for mitochondrial oxidative phosphorylation (OXPHOS). These include 7 of nearly 45 polypeptides of the electron transport chain complex I (ND1-3, ND4L and ND4-6); 1 of the 11 polypeptides of complex III (Cytb), 3 of the 13 polypeptides of complex IV (COI-III), and 2 of the 15 polypeptides of complex V (ATP6 and ATP8). mtDNA also encodes 22 transfer RNAs (tRNAs), as well as the $18 \mathrm{~S}$ and $16 \mathrm{~S}$ ribosomal RNAs (rRNA). tRNAs and rRNAs are necessary for the translation of the respiratory subunit mRNAs within the mitochondrial matrix (Table I) (8-10). The hypervariable region (HVR1: 16024-16383 nt and HVR2: 57-333 nt) or $\mathrm{D}$-loop region is a non-coding sequence; however, it contains the origin of replication of the mtDNA (8-11). The proximity of mtDNA to the site of production of reactive oxygen species (ROS) and the absence of protective histones increase mtDNA susceptibility for acquiring mutations and oxidative damage, causing a mutation rate of 100-1,000-fold higher for mtDNA than nuclear DNA (nDNA) $\left(1.1-1.7 \times 10^{-8}\right.$ per nucleotide site per generation). Moreover, mtDNA damage induced by ROS is more extensive and persists longer than ROS-nDNA injury in human cells $(12,13)$. Mitochondrial DNA encodes only a small number of proteins needed for its molecular architecture and biological functions; hence, additional nuclear-encoded mitochondrial (NEMt) proteins (NEMtPs) are required for mitochondrial biogenesis, assembly of the respiratory chain and the maintenance of mtDNA (Fig. 1) (14). The biogenesis of these organelles, which implies variations in number, size and mass, is highly influenced by factors, such as cell division, renewal, differentiation, oxidative stress, exercise, caloric restriction, low temperature, and mutations in both nDNA and mtDNA $(14,15)$.
Nuclear-encoded genes that participate in mitochondrial biogenesis and function. In addition to the 13 mitochondrial encoded genes, to function properly the mitochondria require $>1,500$ NEMtPs. These proteins are required by the mitochondria to perform DNA replication, transcription and translation processes, as well as to carry out biochemical functions and to maintain its molecular architecture (Fig. 1). Almost $1 \%$ of the products contained in the mitochondria are synthesized in the matrix and the remainder, in the cytosol. Mitochondrial proteins synthesized in the cytosol are encoded by nuclear genes derived from prokaryotic genes that were transferred to the nucleus or that originated during the evolution of eukaryotic cells. Since NEMt genes (NEMtGs or mitonuclear genes) include proteins and enzymes involved in mtDNA replication, transcription and translation, catabolytic pathways, and are components of the mitochondrial import and folding machineries, most of them are strictly essential for life $(16,17)$. One of the most extensively studied NEMtG is the mitochondrial transcription factor $\mathrm{A}(T F A M)$ that regulates mtDNA replication/transcription and is implicated in the dynamics of mtDNA nucleoids (18-21). TFAM expression is promoted by the nuclear respiratory factor transcriptional regulators (NRF)-1 and NRF-2, which are activators of nuclear genes necessary for multiple mitochondrial functions. For example, the biogenesis of the mitochondria is regulated by the induction of peroxisome proliferator-activated receptor $\gamma$ coactivator-1 (PGC-1) $(18,19,22)$. Additionally, it has been reported that the absence of TFAM in knockout mice is responsible for a severe OXPHOS defect, marked reduction in mtDNA content and embryonic lethality (20). Furthermore, the loss of PolgA, encoding a subunit of mitochondrial DNA polymerase, also results in lethality in mice (23). This observation suggests that mutations in NEMtGs can affect functions, such as electron transport and oxidative phosphorylation, protein translocation and mitochondrial biogenesis. The translocase of the outer membrane (TOM) complex is a clear example of the relevant role of mitonuclear genes in the cell, since nearly all mitochondrial pre-proteins are imported via a TOM entry gate (24). From the cytosol to the TOM complex, pre-proteins are guided by molecular chaperones (heat shock protein 90 or heat shock cognate 70) (25); there, TOM20, TOM22 and TOM70 recognize the mitochondrial targeting signals of cytosolic preproteins (Fig. 1). Hence, it is clear that errors in the import and assembly of mitochondrial proteins can result in a disease state in humans (26). Additionally, nDNA genes have also been found to be involved in $>30$ different modified mt-tRNAs, and interestingly, Bandiera et al (27) found a large number of nuclear-encoded miRNAs, designated 'mitomiRs', with differential expression in the mitochondria and cytosol, demonstrating that the majority of mitochondrial miRNAs have both nuclear and mitochondrial-encoded targets.

\section{Mitochondrial DNA variants in human diseases}

Mitochondria are involved in the fundamental cellular process of generating ATP for cellular energy. However, energy metabolism is not the only essential role of mitochondria, since they are also crucial for stress response, cell survival and death, immune response and cell signaling. In consequence, mitochondrial impairment contributes to a wide spectrum of 
Table I. Nuclear DNA and mitochondrial DNA features.

\begin{tabular}{|c|c|c|}
\hline Features & Nuclear DNA & Mitochondrial DNA \\
\hline Base pairs (bp) & 3.2 billion & 16,569 \\
\hline Strand & $\begin{array}{l}\text { Double, lineal, forward (5'-3') } \\
\text { and reverse ( }\left(3^{\prime}-5^{\prime}\right)\end{array}$ & Double, circular, light and heavy \\
\hline Organization & Chromosomes (23 pairs) & Nucleoids \\
\hline Coding region & $2-3 \%$ & $90 \%$ \\
\hline \multicolumn{3}{|l|}{ Genes } \\
\hline Number & 22,000 approx. & $\begin{array}{l}37 \\
\mathrm{~L} \text { (forward): } 8 \text { tRNA and } 1 \text { polypeptide } \\
\text { H (reverse): } 12 \text { polypetides, } 14 \text { tRNAs, } 2 \text { RNAs }\end{array}$ \\
\hline Structure & Exon, intron, intergenic regions & Polycistronic \\
\hline Variants & $\begin{array}{l}\text { SNPs, indel, CNVs, STRs, VNTRs, } \\
\text { translocations, inversions }\end{array}$ & SNPs, Indels, CN \\
\hline Ploidy & Diploid & Polyploid \\
\hline \multicolumn{3}{|l|}{ Genetic code } \\
\hline Transduction codons & 32 & 24 \\
\hline Initiation codon & AUG & AUG, AUA, AUU \\
\hline Stop codon & UAA, UAG, UGA & AGA, AGG \\
\hline Transcription & Multiple & $\mathrm{IT}_{\mathrm{L}}, \mathrm{IT}_{\mathrm{H} 1}, 1 \mathrm{~T}_{\mathrm{H} 2}$ \\
\hline Genotype & Homozygote and heterozygote & Homoplasmic, heteroplasmic \\
\hline Inheritance & Maternal and paternal & Maternal \\
\hline Recombination & Homologous chromosomes & No evidence \\
\hline
\end{tabular}

SNPs, single nucleotide polymorphisms; indel, insertion/deletion; CNVs, copy number variants; STR, short tandem repeat; VNTR, variable number of tandem repeat; $\mathrm{CV}$, copy number.

heterogeneous human conditions (mental disorders, cardiomyopathies, metabolic diseases, immune mediated diseases, aging and cancer); preferentially affecting those tissues with highenergy demands, such as brain, muscle and liver $(12,28,29)$. The strongest evidence linking a mtDNA mutation to a human phenotype is the increased risk of developing blindness in subjects harboring mutations in the mitochondrial encoded complex I genes (ND1-6 and ND4L). These mutations are known to cause Leber hereditary optic neuropathy (LHON), synergistically interacting with a primary LHON mutation to cause a defect in OXPHOS complex I activity (30).

Mitochondrial disorders also cause an overlapping spectrum of diseases. In a case-control study, Hudson et al (29) analyzed mtDNA single nucleotide polymorphisms (SNPs) from 51,106 subjects from the Wellcome Trust Case Consortium, which included patients with ankylosing spondylitis, ischemic stroke, multiple sclerosis, Parkinson's disease, primary biliary cirrhosis, psoriasis, schizophrenia, ulcerative colitis, coronary artery disease, hypertension and type 2 diabetes. The authors observed that mtDNA polymorphisms modify the risk of developing one or more of these diseases. Of note, high-risk alleles were more frequent than protective alleles, indicating that mtDNA is not at equilibrium in the human population, and that recent mutations interact with nuclear loci to modify the risk of developing diseases (29). Notably, polymorphisms that increase the risk of developing two or more diseases were limited to mitochondrial cytochrome $b(C Y B$ : $H 16 R, T 158 A)$ and subunit 3 of cytochrome $c$ oxidase (COIII:
$V 91 L, N 154 S$ ) genes. The $C Y B$ variants H16R and T158A were previously associated with several diseases $(31,32)$. The only non-synonymous polymorphism associated with a reduced risk of various entities was the G10398A (T114A) of ND3, which occurs twice on the human mtDNA phylogeny and has previously been associated with Parkinson's disease and cardiomyopathies (33-36). This polymorphism has been shown to reduce complex I activity, cytosolic calcium levels, and mitochondrial membrane potential, and thus may reduce the levels of ROS (33).

As regards NEMtGs, mutations in >100 genes have been implicated in mitochondrial human diseases (37-40). As an example, mutations in elaC ribonuclease $\mathrm{Z} 2$ (ELAC2) have been found in individuals suffering from infantile-onset hypertrophic cardiomyopathy and complex I deficiency $(39,41)$. Similarly, defects in any step of protein transport due to TOM complex mutations lead to oxidative stress, neurodegenerative diseases, and metabolic disorders (26). Irregularities in mitochondrial targeting signals have also been identified as a cause of pyruvate dehydrogenase (PDH) deficiency. These mutations were described in the amino-terminal targeting signal (N-MTS) of the PDH, which is a subunit of the mitochondrial matrix protein complex. X-linked mutations in the PDH E1 $\alpha$ subunit are the most common cause of PDH deficiency and have been associated to microcephaly and cerebral atrophy (42). Moreover, mutations in nuclear-encoded components of the mitochondrial translation machinery have been shown to be involved in other human diseases (31). To 


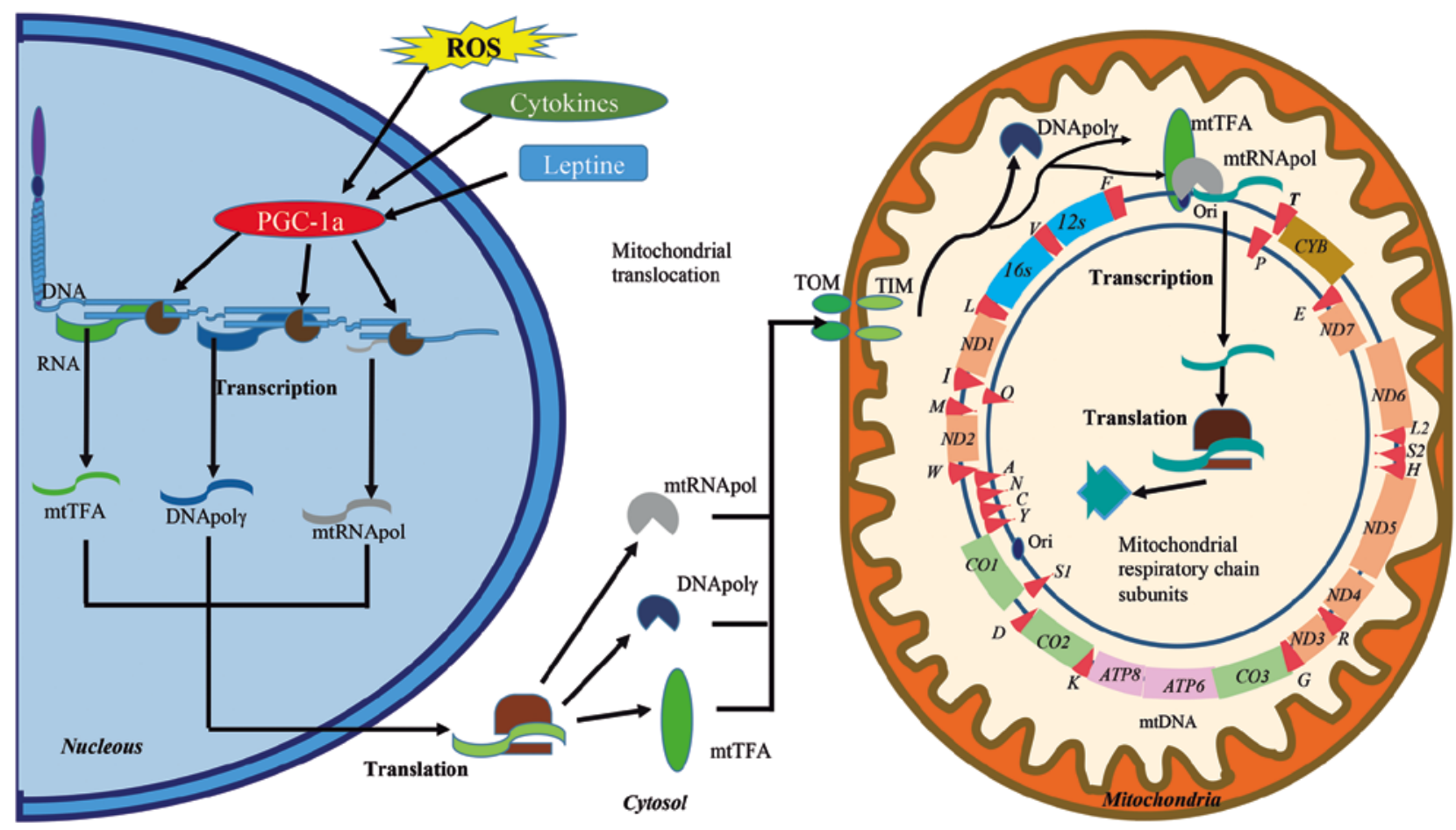

Figure 1. Signaling pathways involved in mitochondrial function and the human mitochondrial DNA (mtDNA) map. Activators, such as reactive oxygen species (ROS), cytokines and leptin activate peroxisome proliferator-activated receptor gamma coactivator-1 (PGC-1a) to promote the transcription of genes that are involved in the mitochondrial transcriptional machinery (DNApol $\gamma$, DNA polymerase $\gamma$; mtTFA, mitochondria transcription factor A; mtRNApol, mitochondrial RNA polymerase, etc.). The mRNAs are directed to the cytoplasm for translation and the resulting proteins are immediately imported into the mitochondria by the translocase of the outer and inner mitochondrial membrane (TOM and TIM, respectively) system. DNApol $\gamma$ is responsible for replication, whereas mtTFA and mtRNApol are actively involved in the initiation of transcription. The formed mRNAs give rise to mitoribosomal subunits, tRNAs, or are translated into the mitoribosomes to generate protein subunits of the mitochondrial respiratory chain complex. mtDNA is a double-stranded (heavy chain: $\mathrm{H}$ and a light chain: L) circular DNA, containing 37 genes, of which, 28 are located in the $\mathrm{H}$ strand and nine in the $\mathrm{L}$ strand. Thirteen of these genes code for essential components of the electron transport complexes (ETC), 22 are transfer RNAs (tRNAs) and two ribosomal RNAs (rRNA). ND1, NADH-ubiquinone oxidoreductase chain 1; ND2, NADH dehydrogenase 2; COI, cytochrome $c$ oxidase I; COII, cytochrome $c$ oxidase 2; ATP8, ATP synthase 8; ATP6, ATP synthase 6; COIII, cytochrome $c$ oxidase 3; ND3, NADH dehydrogenase 3; ND4L, NADH-ubiquinone oxidoreductase chain 4L; ND4, NADH dehydrogenase 4; ND5, NADH dehydrogenase 5; NAD6, NADH dehydrogenase 6; CYB, cytochrome $b . N D$ genes are indicated by orange boxes, $C O$ genes by green boxes, the $C Y B$ gene by a gold box and $A T P$ genes by pink boxes. rRNA is indicated by blue boxes; and tRNA by red triangles.

mention a few, tRNA modifying enzymes (PUS1, TRMU, MTO1), aminoacyl-tRNA synthetases (RARS2, DARS2, YARS2, SARS2, HARS2, AARS2, MARS2, EARS2, FARS2), ribosomal proteins (MRPS16, MRPS22, MRPL3, MRPL12), elongation factors $(G F M 1, E F T s, E F T u)$, translational activators (LRPPRC, TACO1), C12orf62, etc. (43).

\section{Mitochondria variants and cancer}

In pathological conditions, such as cancer, malignant transformation induces reprogramming of cell metabolism and permanent fission and fusion of mitochondria to maintain daughter cells upon cell division. During oncogenic processes, tumor cells not only acquire persistent changes in metabolism to support cell growth, but also other types of mtDNA damage (12). mtDNA mutations have been identified in all types of human tumors, both in the non-coding and coding regions of the mtDNA (Fig. 2). Larman et al, studying different cancer types, found that the frequency of somatic mtDNA mutations ranged from $13 \%$ in glioblastoma to $63 \%$ in rectal adenocarcinomas (44). Notably, the majority of the mtDNA mutations appeared to be homoplasmic (same sequence in all mtDNA molecules) in nature; nevertheless, heteroplasmy (the presence of $>1$ mtDNA sequence in a cell) could contribute to heterogeneous mitochondrial morphologies and correlate with metabolic flexibility and cancer metastasis $(28,45)$. According to their percentage in the cell, mutations may be homoplasmic (>95 to 100\%), high heteroplasmic ( $>20$ to $<95 \%$ ), low heteroplasmic ( $>0.5$ to $20 \%)$ or rare $(0.5 \%$ or less) (46). Surprisingly, $72 \%$ of the reported tumor-specific mtDNA mutations are also found in non-tumor cells (germline variants) of healthy subjects (44). As mtDNA is highly susceptible to acquiring mutations from ROS, in addition to inherited mtDNA mutations, multiple subpopulations of mtDNA could arise during the lifespan, enriching the heteroplasmic condition (mainly in cells with high division rates). Of note, although there is co-occurrence of mtDNA germline variants and somatic mutations, a high proportion of these become homoplasmic in cancer cells $(47,48)$. However, the heteroplasmic threshold effect and the mechanisms underlying their selection towards a homoplasmic state during tumor development are not yet well understood (48).

Warburg's observation was the cornerstone for the study of mitochondrial function in tumor cells. Later, it was observed that the mRNA levels for defined mtDNA encoded genes were upregulated in many human cancer types $(44,49-51)$. In this regard, the first significant finding was the observation that hepatoma cells express hexokinase II, while normal hepatic 


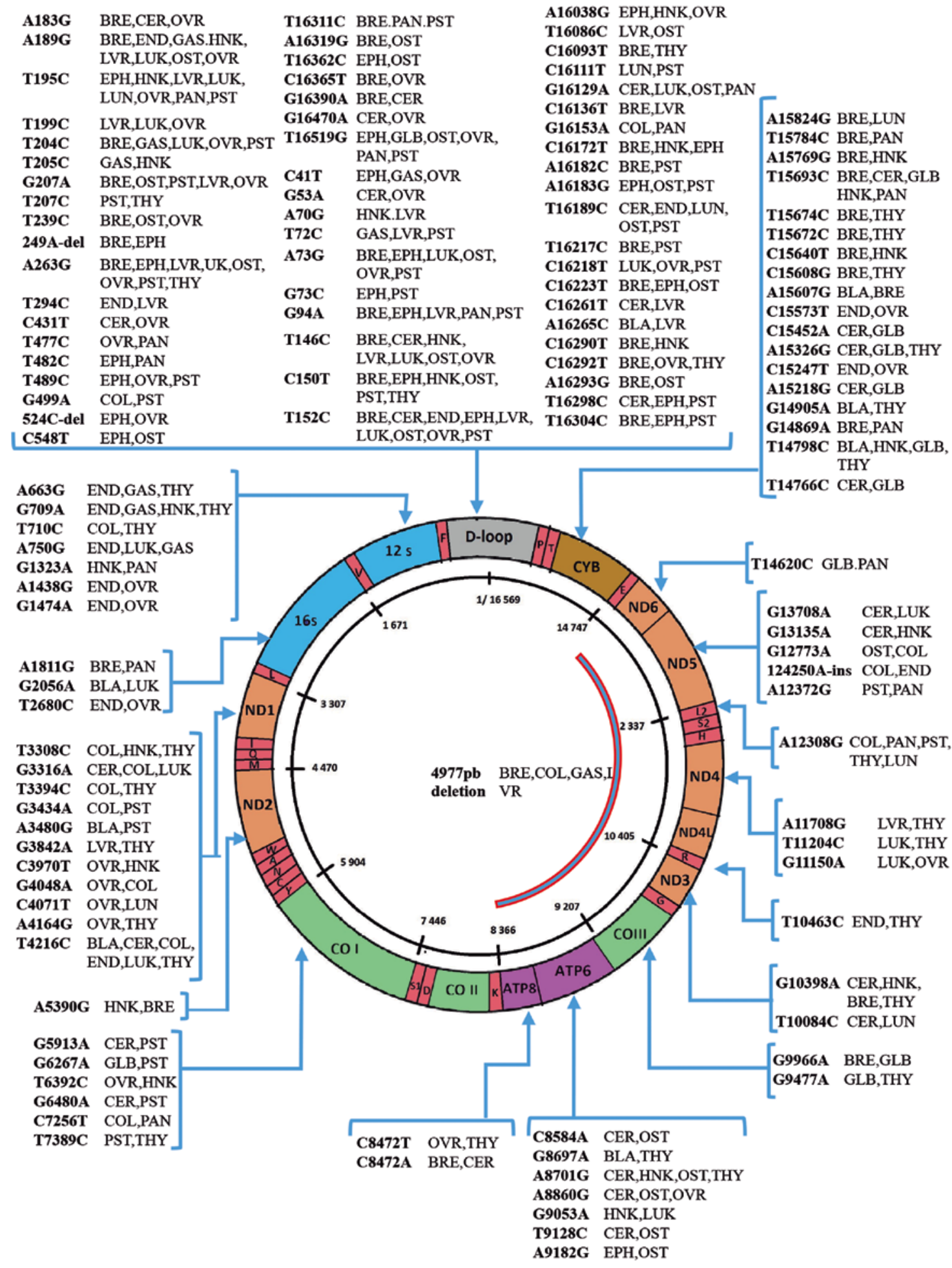

Figure 2. Mitochondrial DNA mutations reported in different types of cancer. The figure shows the mitochondrial (mtDNA) genome diagram and mutations reported in human cancer. mtDNA is a double-stranded circular DNA comprised by 16,569 bases and contain 37 genes. Of these, 13 encode essential components of the electron transport complexes (ETC), 22 are tRNAs and 2 rRNAs. Mutations are named by the locations of the mutated base (C: cytosine, G: guanine, T: thymine, A: adenine). The non-coding D-loop region (gray color) exhibits the higher number of mutations. ND1, NADH-ubiquinone oxidoreductase chain 1; ND2, NADH dehydrogenase 2; COI, cytochrome $c$ oxidase I; COII, cytochrome $c$ oxidase 2; ATP8, ATP synthase 8; ATP6, ATP synthase 6; COIII, cytochrome $c$ oxidase 3; ND3, NADH dehydrogenase 3; ND4L, NADH-ubiquinone oxidoreductase chain 4L; ND4, NADH dehydrogenase 4; ND5, NADH dehydrogenase 5; NAD6, NADH dehydrogenase 6; CYB, cytochrome $b$; BLA, bladder cancer; BRE, breast cancer; CER, cervical cancer; COL, colon cancer; END, endometrial cancer; EPH, esophageal cancer; GAS, gastric cancer; GLB, glioblastoma; HNK, head and neck cancer; LUK, leukemia; LVR, liver cancer; LUN, lung cancer; OTS, osteosarcoma; OVR, ovarian cancer; PNC, pancreatic cancer; PST, prostate cancer; THY, thyroid cancer.

cells express hexokinase IV (glucokinase) (49). Metabolic deregulation and its associated consequences induce a strong selective pressure on tumor cells. Hence, acquiring somatic
mtDNA mutations that impact oxidative phosphorylation seems to be an alternate mechanism for enhancing tumor growth (44). Another important observation is that mutations 
in OXPHOS genes and accumulation of ROS can lead to the oxidation of proteins and their missfolding. To balance this, metastatic cells show high expression of the unfolded protein response $\left(\mathrm{UPR}^{\mathrm{m} t}\right)$, which allows them to survive in this highly stressed environment $(45,52)$.

The mtDNA of cancer cells was first studied by Polyak et al in 1998 (47). They sequenced the mtDNA of 10 human colorectal cancer (CC) cell lines. The authors identified mutations in $70 \%$ of all studied cell lines; many of these occurred in rRNA genes or were missense mutations, with only one frame-shift and one chain-termination mutation (47). Another interesting finding was that tumor cells frequently contained a relatively small number of mitochondria with few mtDNA molecules per mitochondrion. In addition, most of the mtDNA mutations were homoplasmic, derived from a mtDNA somatic mutation initially represented in a heteroplasmic state (44). These data suggested that at least one of the observed tumoral mtDNA mutations could confer a selective advantage to the cancer cell, further supporting the hypothesis that mtDNA somatic mutations play an important role in promoting the proliferation of several types of tumor cells (47). Moreover, Habano et al (53) reported that changes in the length of the polycytosine tract of the HVR2 in the mitochondrial D-loop are the most frequent (44\%) mutations in colorectal tumors. Currently, it is well known that this region is highly mutated in a variety of human cancers (ovarian, thyroid, kidney, liver, lung, colon, gastric, brain, bladder, head and neck, prostate, breast and leukemia), although most of these mutations do not have pathogenic implications, as they are not generating stop-codons, frame-shifts or altering tRNA structures (44). Furthermore, Larman et al (44), analyzing whole-genome data generated by The Cancer Genome Atlas Research Network (CGARN), reported that the majority of coding mutations occurred in the subunits of the electron transport chain complex (NADH dehydrogenase, cytochrome $b$ and cytochrome $c$ oxidase). The atlas includes paired tumor and normal tissue samples from 226 individuals with 5 types of cancer: Colon adenocarcinoma (COAD), rectal adenocarcinoma (READ), acute myeloid leukemia (AML), glioblastoma (GLB) and ovarian serous cystadenocarcinoma (OVR). Highly variable proportions of deleterious tumor-specific mutations across tumor types were found, ranging from $13 \%$ in GLB to $63 \%$ in READ. Another interesting finding was the differential distribution of nonsynonymous (missense and truncating) and synonymous mutations between inherited variants and somatic mutations in all types of cancer (COAD, READ, AML, GLB, OVR). The nonsynonymous mutations were in higher proportion in the tumor mtDNA (86\%) in comparison with the germline mtDNA (31\%). The majority of tumors (94\%) that harbored somatic mtDNA mutations carried at least one nonsynonymous mutation and only $37 \%$ bearer somatic nonsynonymous mutations. Tumors that carried synonymous mutations, but no nonsynonymous mutations accounted for only 3\%. OVR (93\%) exhibited the highest proportion of nonsynonymous mtDNA somatic mutations compared to the rest of the tumor types (COAD, 89\%; READ, 80\%; AML, 78\%; and GLB, 80\%).

The first direct causal connection between a mtDNA mutation and cancer was reported by Petros et al (54) who identified the T8993G (L156R) germline mutation in the ATP6 gene as heteroplasmic in a patient with prostate cancer and demonstrated its tumorigenic capacity in a nude mouse prostate cancer model. The T8993G mutation in ATP6 is known to induce enhanced ROS production, which may be the cause of enhanced tumorigenicity, since ROS are known to affect transcription factors, signal transduction kinases, regulatory phosphatases and angiogenic factors (44). Recently developed techniques, such as next generation sequencing (NGS) have improved our knowledge of the nature of mtDNA mutations thanks to the comparison of tumor and adjacent normal tissue or blood in a wide variety of cancer types. mtDNA variants commonly observed either as germline polymorphisms (or germline mutations) or somatic mutations (cancer cells) include point mutations, mono- or dinucleotide repeats, insertions, deletions and mtDNA copy number variations $(50,51,54)$. The most common mtDNA polymorphisms which have been associated with an increased risk of cancer are T16189C (D-Loop), G10398A (A114T at ND3 gene) and the deletion $\Delta$ mtDNA4977 (55-59). $\Delta$ mtDNA4977 is the most common deletion in the mitochondria, which occurs between nucleotides 8,470 and 13,477 of the human mtDNA. This deletion includes 5 tRNA genes, 4 genes encoding subunits of NADH dehydrogenases, COIII and ATPase genes, creating a smaller mtDNA molecule that leads to a decrease in ATP production and to abnormal ROS generation (Fig. 2) (60).

In addition to the structural abnormalities in mtDNA, fluctuations in mtDNA copy number are frequently described in cancer. For instance, an elevated mtDNA content has been found in primary head and neck squamous cell carcinoma, papillary thyroid carcinoma and endometrial cancer, in contrast to gastric cancer, which exhibits mtDNA depletion (61-63). The mtDNA copy number in cancer may depend upon the specific site of mutation associated with that cancer. Thus, an increase in mtDNA copy number can occur as a compensatory response to mitochondrial dysfunction or to mutations in nuclear genes indirectly involved in controlling mtDNA copy number. Conversely, mutations in the D-loop region, which control mtDNA replication, would be expected to result in a decrease in copy number. In many cases, fewer copies of mtDNA are accompanied by a decrease in the expression of mitochondrial genes, suggesting a suppressed mitochondrial activity in these tumor types. mtDNA impairment may result, not only in mtDNA copy number alterations, but also in the acquisition of new point mutations and deletions in mtDNA, damaged mitochondrial function and changes in cell and tissue viability. Defects in the components of the mtDNA repair machinery, which mediate mtDNA replication and repair, may increase the accumulation of mtDNA mutations, even though mitochondria have nDNA repair pathways, such as base excision repair, miss-match repair and recombinational repair $(12,13)$. Indeed, Reznik et al $(64)$ found that the mtDNA copy number is related to the incidence of key driver mutations that cause cells to become cancerous $(13,14)$. Of note, although the mtDNA copy number can influence the level of transcription of mtDNA genes, not all cancer types exhibit a correlation between the expression of respiratory genes and mtDNA copy number (64). Exogenous and environmental factors, such as industrial by-products, ultraviolet and ionizing radiation, tobacco smoke, chemicals, environmental toxins and therapeutic drugs may also affect mtDNA expression $(13,14)$. 
Haplogroups and cancer risk. Ancient mtDNA SNPs are grouped into haplogroups, which are groups of haplotypes that share several polymorphisms acquired during the expansion and migration of the human population. Haplogroups reflect specific ancestral populations and are the result of sequential accumulation of mitochondrial mutations through maternal lineages; hence, they present continent-specific distributions. The molecular mechanisms underlying the association between mtDNA haplogroups and cancer development remains unclear and controversial results between populations have been reported (65-73). However, specific mtDNA haplogroups have been associated with the risk of prostate cancer, BC, $\mathrm{CC}$, nasopharyngeal cancer, gastric cancer, myelodysplastic syndromes (MS), acute lymphoblastic leukemia, etc. (65-72,74). For example, an over-representation of haplogroup I in Polish cancer patients has been reported (75), haplogroup $U$ has been shown to be associated with an increased risk of developing renal and prostate cancers (65), and haplogroup JT has been shown to be associated with MS susceptibility in North American caucasion subjects (70). Additionally, haplogroups $\mathrm{H}$, $\mathrm{N}$ and $\mathrm{L}$ have been shown to be associated with the risk of developing pancreatic cancer, whereas haplogroup $\mathrm{K}$ has been identified as protective for this type of cancer in participants from the San Francisco Bay Area in California (76). In China, haplogroups D4a and D5a have been found to be associated with an increased the risk of esophageal cancer, while the $\mathrm{N}$ and $\mathrm{M}$ haplogroups have been reported as biomarkers for the good and poor survival of patients with gastric cancer, respectively $(67,69)$. Another study, including 1,503 autopsy cases from Japan (76), reported an association between the haplogroup M7b2, previously associated with leukemia (77) and an increased risk of developing hematologic cancers (76). Nevertheless, some of the most robust association data have been reported for haplogroup T (M184) and the risk of CC in European-American descendants, following the analysis of 2,453 CC cases and 11,930 multi-ethnic controls (68).

Nuclear-encoded genes, mtDNA biogenesis and function in cancer. While a number of studies on cancer have focused on nDNA mutations, less research has been directed at determining the influence of germline variants and somatic mutations in NEMtGs and mitochondrial genes on organelle dysfunction and cancer development. It is well known that mutations in nuclear-encoded components of the mitochondrial translation machinery accumulate non-repaired nDNA and mtDNA that may promote cellular transformation and tumor development. Mutations in nuclear genes responsible for mtDNA biosynthesis and integrity maintenance, such as POLG, mtTFA, $P G C$-1, NRF-1, NRF-2, isocitrate dehydrogenase (IDH), SDH family members (SDHA, SDHB, SDHC and $S D H D)$, fumarate hydratase $(F H)$, SIRT1-3, POLG, TWINKLE and OPAl are frequently implicated in carcinogenic processes $(74,78,79)$. In fact, heterozygous germline mutations in $S D H B, S D H C$, $S D H D$ and $S D H A F 2$ cause hereditary paragangliomas and pheochromocytomas (80). POLG is known as the only DNA polymerase that functions in human mitochondria. Due to its ability to bypass lesions by translation synthesis, $P O L G$ is vital for maintaining the genetic integrity of mtDNA. Mutations in this gene can promote mtDNA mutations, the accumulation of unrepaired lesions or can even block DNA replication in cancer (4,6-13). Furthermore, IDH1 and IDH2, mitochondrial and TCA cycle-related proteins, are frequently mutated in tumors, such as glioblastoma. In fact, studies on GLB and AML have identified recurrent missense mutations that impact specific residues of the nuclear genes $I D H 1$ and $I D H 2(78,79)$. Notably, it has been observed that tumors carrying $I D H$ mutations have few or no somatic mtDNA mutations (79).

The abnormal expression of several NEMtGs is a common finding in all steps of cancer development and progression. For example, TNF receptor-associated protein 1 (TRAP1) is a protein that plays a role in the regulation of proteostasis, mitochondrial apoptosis and suppression of ROS production in the mitochondria of tumor cells, through regulation of folding and stability of selective proteins. In fact, it has been reported that TRAP1 overexpression favors resistance to standard chemotherapeutic agents (81). The overexpression of genes involved in the activation of the UPR ${ }^{\mathrm{mt}}$ has also been observed in metastatic cells. The UPR ${ }^{\mathrm{mt}}$ system protects from protein misfolding and oxidation; however, it might also maintain deleterious mtDNA mutations conferring advantages that facilitate cancer cell metastasis $(52,82)$.

\section{Mitochondrial DNA variants in breast cancer}

The recognition of the importance of mtDNA mutations as a relevant feature in $\mathrm{BC}$ development, metastasis and resistance to treatment, has occurred over the past decade $(48,83,84)$. Both mtDNA germline variants and tumor mutations have been involved in BC (Table II). As with other types of cancer, the D-loop region (16024-576 nt), mainly the HVR1 and HVR2 regions, is an important mitochondrial mutation hotspot $(48,83,85)$. This region has been reported to be $\sim 60$-fold more susceptible to mutations than other regions of the mitochondrial genome (55,86-88). The T16189C, C16207T, T16519C, T239C and A263G polymorphisms, located in the D-loop region, are frequently associated with the risk of BC (85-87). By contrast, the T16183C, C16223T, T16362C, $\mathrm{A} 73 \mathrm{G}$ and $\mathrm{C} 150 \mathrm{~T}$ polymorphisms, have been found to be enriched in controls compared to BC patients, suggesting that they could protect for this disease (86). Of these, T16189C is the most common polymorphism that is associated with the risk of $\mathrm{BC}(75,89,90)$. The $\mathrm{T}$ to $\mathrm{C}$ change in the wild-type (C5TC4) generates a long run of $\mathrm{C}$ residues considered to be a source of enhanced instability $(55,85,87,88,91)$. This abnormality often leads to heteroplasmic length variation of the poly- $C$ tract ( $>10$ cytosines) and a correlation has been observed between the poly-C variants and the mtDNA copy numbers (59), as subjects who have an interrupted poly-C carry higher mtDNA copy number, in contrast to those with an uninterrupted poly-C, suggesting that the T16189C variant may affect mtDNA replication (92).

Coding mitochondrial variants have also been implicated in the risk of BC. On one hand, the A4727G, G9055A, C6296A, G9947A, A8860G, A10044G, A10283G, T11233C and $\mathrm{C} 11503 \mathrm{~T}$ variants increase the risk, and on the other hand, the T3197C and G13708A SNPs decrease the risk of developing this neoplasia $(85,86,88,93-95)$. In terms of deletions, the 2463delA, 6298delT and the $\Delta$ mtDNA4977 polymorphisms have been identified as susceptibility factors for BC; however, $\triangle$ mtDNA4977 is the most commonly implicated in the breast 
carcinogenesis process $(88,96)$. The mechanisms that promote tolerance to these deletions or contribute to their propagation in the tumor cells are unknown (82). Additionally, differential contribution and interaction between germline variants have been reported to increase BC susceptibility. For example, G10398A has been shown to be associated with an increased risk of BC in European-American, Polish and Malay populations, but not in Hindu and African-American women (57,75,84,97-100). Furthermore, T4216C confers a risk of BC only in combination with the G10398A germline variant (97).

It is relevant to state that in addition to the G6267A somatic mutation, the germline variants T14110C, G14207A and D310 (from nucleotide positions 303 to 315 and interrupted by a $\mathrm{T}$ in position 310$)$ are very common in BC cases $(96,101,102)$. The poly-cytidine stretch D310 is the most common, reaching $92 \%$ of the tumor samples; thus, it has been suggested as a potential starting point for the clonal expansion of malignant cells and may be a clinical marker for breast tumorigenesis $(85,88,101,103-108)$. Alhomidi et al, in 2013, supported this hypothesis, reporting that $32.5 \%$ of patients from India with BC were D310 carriers (108).

Apart from somatic mtDNA mutations, studies have identified mtDNA mutation (varying degrees, different sites, and different types) in nearly $60 \%$ of BCs tumors $(87,88,95,101)$; however, the question of whether the mutations help drive the tumor or are bystander events remains unanswered $(76,83)$. McMahon and LaFramboise (83), in a study that included 99 normal-tumor paired BC samples, identified 142 somatic mutations; however, many of these have been reported as germline variants. G567A, G766A, G1333A, A2085G, G2621A, G5043 and G11346A were identified in only one patient, as examples of somatic mutations (described exclusively in breast tumor tissue) $(83,109)$. Other matched blood-tumor mtDNA sample studies have also shown that most somatic mutations are singletons arising in a single patient and interestingly, are present in a heteroplasmic state in the tumor, but not in mtDNA from normal tissues. It has been suggested that many putative somatic mutations are in undetected germline heteroplasmies that have undergone clonal expansion in the tumor $(46,83,110)$.

With regard to the impact of mtDNA content in $\mathrm{BC}$, a lower mtDNA content has been observed in BC tumors when compared to their surrounding normal epithelium; however, these data are inconsistent (111).

Haplogroups and breast cancer. The important role of haplogroups in different human conditions such as aging, neurodegenerative diseases, metabolic diseases, as well as BC (Table III) have also been explored. Currently, it is considered that metabolism and sensitivity to oxidative stress differs among mitochondrial haplogroups (112).

Studies performed on the Polish population have demonstrated the overrepresentation and under-representation of haplogroups $\mathrm{I}$ and $\mathrm{H}$, respectively, in patients with $\mathrm{BC}$, in comparison with healthy groups. These data suggest that the presence of different polymorphisms given in the haplogroup may be fundamental for the carcinogenic process (75). Furthermore, an association between haplogroups and BRCA1 and BRCA2 mutations has been reported. Tommasi et al (113) found that haplogroups $\mathrm{X}$ and $\mathrm{H}$ were significantly more frequent in subjects bearing mutations in the $B R C A l$ and
$B R C A 2$ genes, respectively. Additionally, it has recently been observed that haplogroup T1a1 may modify the individual risk of acquiring the disease in BRCA2 mutation carriers (114). Likewise, Rao et al (115), studying 92 triple-negative BC (TNBC) patients of African-American $(n=31)$, caucasion $(n=31)$ and Hispanic $(n=30)$ origin, found that Nigerian $(29 \%)$, Cameroon (26\%), Sierra Leone (16\%) and Guinea-Bissau (13\%) haplogroups were highly prevalent in African-American patients; while the $\mathrm{H}(29 \%), \mathrm{U}(23 \%), \mathrm{K}(13 \%), \mathrm{V}(7 \%)$, and $\mathrm{J}(7 \%)$ haplogroups accounted for $79 \%$ of all haplogroups identified in caucasian-derived populations. As has been previously reported, haplogroups A (34\%), B (17\%) and C $(13 \%)$ are the most frequent in Hispanic patients. Notably, the authors found that non-caucasian haplogroups represent almost $64 \%$ of TNBC patients, which is in accordance with data showing that TNBC is more common in African- and Hispanic-derived populations (115). Although some of these studies have provided controversial findings and statistically underpowered results, the European haplogroup N, defined by the G10398A germline variant, has been reported as a risk factor for BC, particularly in women of African-American and Indian origin (96,116-118). Additionally, Bai et al (85), studying a caucasian population, found that haplogroup $\mathrm{K}$ (G10398A and T16189C) increased the risk of BC, whereas haplogroup $U$ conferred protection against this disease. Moreover, Darvishi et al (99) re-analyzed approximately 1,000 mitochondrial DNA sequences and found an association between the distribution of haplogroup $\mathrm{N}$ and the incidence of sporadic BC. This was corroborated through a case control study, where they also observed association of the A10398C germline variant with sporadic BC.

Mutations in nuclear-encoded genes that participate in $m t D N A$ biogenesis and $B C$. It is well known that mutations in nuclear encoded genes, such as BRCA1, BRCA2, TP53, PTEN, $C H E K 2$ and $C H E K 1$, are commonly associated with a high risk of developing BC. Moreover, as the majority of mitochondrial proteins are nuclear encoded and post-translationally imported in the mitochondria, the nuclear/mitochondrial connection in $\mathrm{BC}$ is also altered. However, the most notable association between the mitochondrial function and nuclear encoded genes relates to the OXPHOS system since 79 of its components are encoded by nDNA. In fact, none of the subunits of complex II are encoded by mtDNA $(74,78,119)$. Hossein and Houshmand (120) used algorithms to determine that the mitochondrial deletion $\triangle \mathrm{mtDNA} 4977$ in association with alterations in nuclear genes (such as BRCA, ER and TP53 genes) led to a phenotype of premature aging and BC (95). Moreover, Jandova et al (121) reported that the copy number of mtDNA can produce differential expression levels of matrix metalloproteinase 9 (MMP9) and collagen, type I, a1 (Colla), which are capable of triggering the malignancy. Notably, $M M P 9$ has been shown to be involved in several types of cancer and metastasis. Additionally, expression analyses have also revealed an association between the expression of NEMtGs and BC subtypes. Furthermore, mitochondrial membrane respiratory chain complex I and IV and ATP synthesis were reduced, in both epithelial and stromal cancer cells compared to normal breast cells. Additionally, MRPL12, POLG and RNASEH1 were upregulated in cancerous stromal cells (122). 
Table II. Common germline variants associated with breast cancer.

\begin{tabular}{|c|c|c|c|c|c|}
\hline Population & Mutation & Gene & OR (CI 95\%) & P-value & Refs. \\
\hline African-American & G10398A & $N D 3$ & $1.6(1.10-2.31)$ & 0.013 & $(57)$ \\
\hline Canadian & $310 \mathrm{C}$-ins & D-loop & - & 0.0001 & (106) \\
\hline \multirow[t]{9}{*}{ Chinese } & 2463A-del & $R N R 2$ & $8.05(1.023-63.34)$ & 0.022 & $(66,87,96)$ \\
\hline & C6296T & COI & $4.464(0.55-35.90)$ & 0.038 & \\
\hline & 6298T-del & $\mathrm{COI}$ & $4.464(0.55-35.90)$ & 0.038 & \\
\hline & $8460-13477 \mathrm{del}$ & $\begin{array}{l}A T P 8, A T P 6, C O 3, T G, N D 3, T R \\
N D 4 L, N D 4, T H, T S 2, T L 2, N D 5\end{array}$ & - & - & \\
\hline & A 8860 & ATPG & $5.254(0.65-41.92)$ & 0.021 & \\
\hline & A10397G & ND3 & $3.11(1.07-9.06)$ & 0.03 & \\
\hline & G10398A & ND3 & $1.77(1.00-3.14)$ & 0.05 & \\
\hline & 13237A-del & ND5 & $4.85(0.60-38.86)$ & 0.037 & \\
\hline & $\mathrm{T} 16189 \mathrm{C}$ & D-loop & $2.36(1.14-4.88)$ & 0.019 & \\
\hline \multirow[t]{7}{*}{ European-American } & T3197C & $R N R 2$ & $0.31(0.13-0.75)$ & 0.004 & $(85,98)$ \\
\hline & G9055A & ATP6 & $3.03(1.63-5.63)$ & 0.0004 & \\
\hline & A10397G & ND3 & - & 0.03 & \\
\hline & G10398A & $N D 3$ & $1.79(1.14-2.81)$ & 0.01 & \\
\hline & G13708A & ND5 & $0.47(0.24-0.92)$ & 0.002 & \\
\hline & $\mathrm{T} 16519 \mathrm{C}$ & D-loop & $1.98(1.25-3.12)$ & 0.003 & \\
\hline & $\mathrm{T} 16519 \mathrm{C}$ & D-loop & $1.98(1.25-3.12)$ & 0.003 & \\
\hline Indian & G10398A & $N D 3^{*}$ & $1.73(1.13-2.66)$ & 0.01 & (99) \\
\hline \multirow[t]{14}{*}{ Italian } & A $153 \mathrm{G}$ & D-loop & $19(1.8-201.9)$ & 0.009 & $(107,113)$ \\
\hline & $\mathrm{T} 195 \mathrm{C}$ & D-loop & $6(1.12-31.99)$ & 0.04 & \\
\hline & G225A & D-loop & $12.7(1.18-136.28)$ & 0.03 & \\
\hline & $\mathrm{T} 226 \mathrm{C}$ & D-loop & $12.7(1.18-136.28)$ & 0.03 & \\
\hline & G3918A & $N D 1$ & - & - & \\
\hline & G11719A & ND4 & $13.2(2.13-82.13)$ & 0.005 & \\
\hline & G11900A & ND4 & - & - & \\
\hline & $\mathrm{T} 12344 \mathrm{~A}$ & ND5 & - & - & \\
\hline & G13708A & ND5 & - & - & \\
\hline & G14869A & $C Y B$ & - & - & \\
\hline & $\mathrm{C} 16093 \mathrm{~T}$ & D-loop & - & - & \\
\hline & $\mathrm{T} 16183 \mathrm{C}$ & D-loop & $12.7(1.18-136.28)$ & 0.03 & \\
\hline & $\mathrm{C} 16278 \mathrm{~T}$ & D-loop & $7.3(1.14-4.88)$ & 0.03 & \\
\hline & $\mathrm{T} 16519 \mathrm{C}$ & D-loop & $21(2.15-204.6)$ & 0.003 & \\
\hline Malay & G10398A & ND3 & $2.29(1.25-4.20)$ & 0.007 & $(100)$ \\
\hline \multirow[t]{18}{*}{ Polish } & A73G & D-loop & - & 0.001 & $(75,94)$ \\
\hline & $\mathrm{C} 150 \mathrm{~T}$ & D-loop & - & 0.001 & \\
\hline & $\mathrm{T} 152 \mathrm{C}$ & D-loop & - & 0.059 & \\
\hline & $\mathrm{T} 239 \mathrm{C}$ & D-loop & - & 0.001 & \\
\hline & A263G & D-loop & - & 0.001 & \\
\hline & A4727G & $N D 2$ & - & - & \\
\hline & G9947A & COIII & - & - & \\
\hline & A10044G & $T G$ & - & - & \\
\hline & A10283G & ND3 & - & - & \\
\hline & $\mathrm{T} 11233 \mathrm{C}$ & $N D 4$ & - & - & \\
\hline & $\mathrm{C} 11503 \mathrm{~T}$ & $N D 4$ & - & - & \\
\hline & $\mathrm{T} 16183 \mathrm{C}$ & D-loop & - & 0.036 & \\
\hline & $\mathrm{T} 16189 \mathrm{C}$ & D-loop & - & 0.004 & \\
\hline & $\mathrm{C} 16192 \mathrm{~T}$ & D-loop & - & 0.023 & \\
\hline & $\mathrm{T} 16207 \mathrm{C}$ & D-loop & - & 0.023 & \\
\hline & $\mathrm{C} 16223 \mathrm{~T}$ & D-loop & - & 0.001 & \\
\hline & $\mathrm{T} 16362 \mathrm{C}$ & D-loop & - & 0.001 & \\
\hline & $\mathrm{T} 16519 \mathrm{C}$ & D-loop & - & 0.003 & \\
\hline \multirow[t]{4}{*}{ Spanish } & G3010A & $R N R 2$ & $0.73(0.44-1.00)$ & 0.047 & (116) \\
\hline & T3197C & $R N R 2$ & $2.72(1.14-7.18)$ & 0.015 & \\
\hline & A12308G & $T L 2$ & $0.66(0.46-0.94)$ & 0.019 & \\
\hline & $\mathrm{T} 16519 \mathrm{C}$ & D-loop & $0.74(0.55-0.99)$ & 0.039 & \\
\hline Taiwanese & mtDNA depletion & All & - & 0.0008 & $(125)$ \\
\hline
\end{tabular}

OR, odds ratio; CI, confidence interval; $R N R 2$, rRNA subunit $16 \mathrm{~s} ; N D 1, \mathrm{NADH}$ dehydrogenase subunit $1 ; N D 2, \mathrm{NADH}$ dehydrogenase subunit $2 ;$;D3, NADH dehydrogenase subunit 3; ND4, NADH dehydrogenase subunit 4; ND4L, NADH dehydrogenase subunit 4L; ND5, NADH dehydrogenase subunit 2; COI, cytochrome oxidase subunit $1 ; C O I I$, cyto-chrome oxidase subunit $2 ; C Y B$, cytochrome $b ; A T P 6$, ATP synthase subunit $6 ; A T P 8$, ATP synthase subunit $8 ;$; $G$, tRNA glycine; $T R$, tRNA arginine; $T H$, tRNA histidine; $T S 2$, tRNA serine 2; $T L 2$, tRNA leucine. 
Table III. Frequency of haplogroups associated with breast cancer.

\begin{tabular}{|c|c|c|c|c|c|c|c|c|}
\hline $\begin{array}{l}\text { Haplo- } \\
\text { group }\end{array}$ & SNPs & Population & $\begin{array}{c}\mathrm{N} \\
\text { Controls/cases }\end{array}$ & $\begin{array}{l}\text { Frequency } \\
\quad(\%)\end{array}$ & Effect & OR (CI 95\%) & P-value & Refs. \\
\hline D5 & $\begin{array}{l}\text { C150T, T1107, } \\
\text { A5301G, A10397G }\end{array}$ & Chinese & $104 / 114$ & 12.9 & Increased risk & $3.11(1.07-9.06)$ & 0.030 & (66) \\
\hline $\mathrm{K}$ & $\begin{array}{l}\text { A10550G, T11299C, } \\
\text { T14798C, T16224C, } \\
\text { T16311C }\end{array}$ & $\begin{array}{l}\text { European- } \\
\text { American }\end{array}$ & $156 / 260$ & 18.6 & $\begin{array}{l}\text { Increased risk of } \\
\text { hereditary cancer }\end{array}$ & $3.03(1.63-5.63)$ & 0.0004 & (85) \\
\hline $\mathrm{H}$ & G2706A, T7028C & $\begin{array}{l}\text { Polish } \\
\text { Italian }\end{array}$ & $\begin{array}{c}44 / 100 \\
10 / 10\end{array}$ & $\begin{array}{l}36 \\
40\end{array}$ & $\begin{array}{l}\text { Protection } \\
\text { Increased risk } \\
\text { of } B R C A 2 \\
\text { mutation carriers }\end{array}$ & $\begin{array}{c}0.636(0.51-0.74) \\
-\end{array}$ & $\begin{array}{l}0.019 \\
0.05\end{array}$ & $\begin{array}{l}(75) \\
(113)\end{array}$ \\
\hline I & T10034C, G16129A & Polish & $44 / 100$ & 14 & Increased risk & - & 0.017 & (75) \\
\hline M & $\begin{array}{l}\text { T489C, C10400T, } \\
\text { T14783C, G15043A }\end{array}$ & Chinese & $104 / 114$ & 66.3 & $\begin{array}{l}\text { Increased risk. Protection } \\
\text { against metastasis }\end{array}$ & $1.77(1.03-3.07)$ & 0.040 & (62) \\
\hline $\mathrm{N}$ & $\begin{array}{l}\text { G8701A, C9540T, } \\
\text { G10398A, C10873T, } \\
\text { A15301G }\end{array}$ & Chinese & $34 / 70$ & 47 & Risk of metastasis & $0.39(0.17-0.94)$ & 0.036 & (66) \\
\hline $\mathrm{U}$ & $\begin{array}{l}\text { A11467G, A12308G, } \\
\text { G12372A }\end{array}$ & $\begin{array}{l}\text { European- } \\
\text { American }\end{array}$ & $156 / 260$ & 7.7 & $\begin{array}{l}\text { Decreased risk of } \\
\text { hereditary cancer }\end{array}$ & $0.37(0.19-0.73)$ & 0.0023 & $(85)$ \\
\hline $\mathrm{X}$ & $\begin{array}{l}\text { T6221C, C6371T, } \\
\text { A13966, T14470C, } \\
\text { T16189C, C16278T }\end{array}$ & Italian & $10 / 10$ & 60 & $\begin{array}{l}\text { Increased risk of } B R C A l \\
\text { mutation carriers }\end{array}$ & - & 0.04 & (113) \\
\hline T1a1 & $\begin{array}{l}\text { T9899C, A16163G, } \\
\text { C16186T, T152C, } \\
\text { T195C }\end{array}$ & $\begin{array}{l}\text { Multi- } \\
\text { national }\end{array}$ & $3989 / 3698$ & 9.3 & $\begin{array}{l}\text { Decreased risk of } B R C A 2 \\
\text { mutations carriers }\end{array}$ & $0.62(0.40-0.95)$ & 0.03 & (114) \\
\hline
\end{tabular}

SNPs, single nucleotide polymorphisms; OR, odds ratio; CI, confidence interval.

$m t D N A$ variants and BC subtypes and survival. Few studies have been conducted to clarify whether there is a correlation between mtDNA germline variants or somatic mutations and $\mathrm{BC}$ subtypes. Thus far, there has been no direct association of mutations with the intrinsic subtypes of this neoplasia; however, Lin et al (123) observed that the D310 germline variant was associated with an advanced stage of the tumor and with negative Her2/neu expression. Tommasi et al (113) found that the $\mathrm{T} 16126 \mathrm{C}$ germline variant was more frequent, but not exclusive, in estrogen- and progesterone receptor-negative tumors. Nevertheless, the authors detected that C150T was exclusive to patients with hereditary BC, as was T16519C, which was found in $90 \%$ of individuals carrying mutations in BRCA1. Blein et al (124) sequenced blood mtDNA from 436 women, with a positive familial BC history, but negative for $B R C A 1 / 2$ pathogenic mutations, diagnosed with $\mathrm{BC}$, and found an enrichment of mutations in MT-ATP6 (86.5 variants/Mb) and $M T-C Y B(84.1$ variants/Mb), but no association between the rate or type of mutations. Moreover, McMahon and LaFramboise (83) observed that alterations in heteroplasmy levels were more significant in HER2-positive tumors than in HER2-negative tumors.

The impact of the mtDNA mutation rate and mtDNA content and their correlation with prognosis and survival have also been investigated. A higher mutational burden and a low copy number of mtDNA have been associated with a worse overall survival, in contrast to patients carrying a low mutation rate or high mtDNA content; however, these results remain inconclusive $(111,125)$.

\section{Mitochondria DNA mutations and response to therapy in breast cancer}

Widespread attention has been paid to mitochondria mutations. This is a not a recent phenomenon, and it fits into the broader historical interest in studying the size, evolution and function of genomes. The first complete human mtDNA sequenced was in 1981; currently, >3,000 complete mitochondrial genomes have been sequenced (109). The unique structure and function of mitochondria make them an excellent model system to identify and answer biological and medical issues where other approaches exhibit technical difficulties. As the mitochondria control both energy metabolism and susceptibility towards apoptotic cell death, mtDNA mutations have been suggested to play important roles in breast carcinogenesis and drug-resistance. Thus, the landscape of driving tumor mtDNA mutations could be used for the design of clinical trials and development of new anti-neoplasic therapies. In this regard, the role of mitochondrial dysfunction and cancer therapy has been widely investigated. Recently, Farnie et al (126) demonstrated that tumors with high mitochondrial mass (mito-high) were specifically enriched in the number of cancer stem-like cells (CSCs), which are involved in tumor recurrence and metastasis. Furthermore, these mito-high breast CSCs exhibited resistance 
to DNA damage following antineoplastic treatment. Based on the 'Endo-symbiotic Theory of Mitochondrial Evolution', it is suggested that antibiotics against mitochondria could be used to modify mitochondrial mass within CSCs. In fact, the FDA has already approved drugs/antibiotics that target mitochondria to eradicate CSC activity (metformin and pyrvinium pamoate, salinomycin) as well as inhibitors of mitochondrial biogenesis and mitochondrial translation (erythromycins, tetracyclines and glycylcyclines) $(126,127)$. Notably, doxycycline and azithromycin have already exhibited significant efficacy in treatment-resistant cancer patients with lymphoma and non-small cell lung tumors, respectively $(128,129)$.

The steep rise in interest in the study of mitochondrial mutations is also due to the fact that mtDNA mutations play a role in many other human diseases, opening a paradigm shift that suggests that mitochondrial mutations will contribute to our understanding of tumor biology in the mammary gland. In fact, Teixeira et al (130) found that the mitochondria were also involved in stem cell differentiation, showing that blocking any of the 13 key proteins linked to ATP synthase disrupted or stalled egg development in fruit flies. Certainly, the recognition of the widespread applicability of studying the role of mitochondria and the biological implications of mtDNA may will strongly improve the development of new means with which to treat human common diseases, including BC.

\section{Conclusions}

As mtDNA mutations and mtDNA copy number have been found to play important roles in breast carcinogenesis, the landscape of driving tumor mtDNA mutations may be used for the design of clinical trials and the development of novel anti-neoplastic therapies. Moreover, the suggestion that mtDNA copy number is associated with the severity of the disease could identify cases with better or worse survival. It is clear that NGS technologies have resulted in an unprecedented ability to understand mtDNA structure; however, the challenge is to determine whether and which mutations or germline variants carry biological significance. In addition, meriting further investigation are other aspects of mitochondrial genomes which undoubtedly are involved in human diseases, these aspects include chromosome structure, transcriptional and translational architecture, and modes of repair and replication.

\section{Acknowledgements}

Not applicable.

\section{Funding}

This study was funded by Consejo Nacional de Ciencia y Tecnología (CONACyT) through the program Fondo Sectorial de Investigación en Salud y Seguridad Social (S0008-2016-1-272618) and by the Internal Research Program of the National Institute of Genomic Medicine, Mexico (C2_19/2009).

\section{Availability of data and materials}

Not applicable.

\section{Authors' contributions}

SJM and CJPA reviewed the literature and wrote the first draft of the manuscript. SJM, EL and AHM were involved in the conception of the review and critically reviewed the final version. All authors read and approved the final manuscript.

\section{Ethics approval and consent to participate}

Not applicable.

\section{Consent for publication}

Not applicable.

\section{Competing interests}

The authors declare that they have no competing interests.

\section{References}

1. World Cancer Research Fund International: BC Statistics. http://www.wcrf.org/int/cancer-facts-figures/data-specific-cancers/ breast-cancer-statistics Accessed January 19, 2018.

2. Breastcancer.org: U.S. BC statistics. http://www.breastcancer.org/ symptoms/understand_bc/statistics. Accessed January 19, 2018.

3. Hanahan D and Weinberg RA: Hallmarks of cancer: The next generation. Cell 144: 646-674, 2011.

4. Warburg O: On the origin of cancer cells. Science 123: 309-314, 1956.

5. Havas KM, Milchevskaya V, Radic K, Alladin A, Kafkia E, Garcia M, Stolte J, Klaus B, Rotmensz N, Gibson TJ, et al: Metabolic shifts in residual breast cancer drive tumor recurrence. J Clin Invest 127: 2091-2105, 2017.

6. Wu W and Zhao S: Metabolic changes in cancer: Beyond the Warburg effect. Acta Biochim Biophys Sin (Shanghai) 45: 18-26, 2013.

7. Bardella C, Pollard PJ and Tomlinson I: SDH mutations in cancer. Biochim Biophys Acta 1807: 1432-1443, 2011.

8. Bogenhagen DF: Mitochondrial DNA nucleoid structure. Biochim Biophys Acta 1819: 914-920, 2012.

9. Andrews RM, Kubacka I, Chinnery PF, Lightowlers RN, Turnbull DM and Howell N: Reanaly-sis and revision of the Cambridge reference sequence for human mitochondrial DNA. Nat Genet 23: 147, 1999.

10. Wallace DC and Chalkia D: Mitochondrial DNA genetics and the heteroplasmy conundrum in evolution and disease. Cold Spring Harb Perspect Biol 5: a021220, 2013.

11. Stewart JB and Chinnery PF: The dynamics of mitochondrial DNA heteroplasmy: Implications for human health and disease. Nat Rev Genet 16: 530-542, 2015.

12. Akhmedov AT and Marín-García J: Mitochondrial DNA maintenance: An appraisal. Mol Cell Biochem 409: 283-305, 2015.

13. Yakes FM and Van Houten B: Mitochondrial DNA damage is more extensive and persists longer than nuclear DNA damage in human cells following oxidative stress. Proc Natl Acad Sci USA 94: 514-519, 1997.

14. Egea PF, Stroud RM and Walter P: Targeting proteins to membranes: Structure of the signal recognition particle. Curr Opin Struct Biol 15: 213-220, 2005.

15. Baker MJ, Frazier AE, Gulbis JM and Ryan MT: Mitochondrial protein-import machinery: Correlating structure with function. Trends Cell Biol 17: 456-464, 2007.

16. Neupert W and Herrmann JM: Translocation of proteins into mitochondria. Annu Rev Biochem 76: 723-749, 2007.

17. Lill R and Mühlenhoff U: Maturation of iron-sulfur proteins in eukaryotes: Mechanisms, connected processes, and diseases. Annu Rev Biochem 77: 669-700, 2008.

18. Virbasius JV and Scarpulla RC: Activation of the human mitochondrial transcription factor A gene by nuclear respiratory factors: A potential regulatory link between nuclear and mitochondrial gene expression in organelle biogenesis. Proc Natl Acad Sci USA 91: 1309-1313, 1994. 
19. Hendrickson SL, Lautenberger JA, Chinn LW, Malasky M, Sezgin E, Kingsley LA, Goedert JJ, Kirk GD, Gomperts ED, Buchbinder SP, et al: Genetic variants in nuclear-encoded mitochondrial genes influence AIDS progression. PLoS One 5: e12862, 2010.

20. Scarpulla RC: Nucleus-encoded regulators of mitochondrial function: Integration of respiratory chain expression, nutrient sensing and metabolic stress. Biochim Biophys Acta 1819: 1088-1097, 2012.

21. Kasashima $\mathrm{K}$ and Endo $\mathrm{H}$ : Interaction of human mitochondrial transcription factor $\mathrm{A}$ in mitochondria: Its involvement in the dynamics of mitochondrial DNA nucleoids. Genes Cells 20: 1017-1027, 2015.

22. Lee HC and Wei YH: Mitochondrial biogenesis and mitochondrial DNA maintenance of mammalian cells under oxidative stress. Int J Biochem Cell Biol 37: 822-834, 2005.

23. Hance N, Ekstrand MI and Trifunovic A: Mitochondrial DNA polymerase gamma is essential for mammalian embryogenesis. Hum Mol Genet 14: 1775-1783, 2005.

24. Mokranjac D and Neupert W: Cell biology: Architecture of a protein entry gate. Nature 528: 201-202, 2015.

25. Fan AC, Bhangoo MK and Young JC: Hsp90 functions in the targeting and outer membrane translocation steps of Tom70-mediated mitochondrial import. J Biol Chem 281: 33313-33324, 2006.

26. MacKenzie JA and Payne RM: Mitochondrial protein import and human health and disease. Bi-ochim Biophys Acta 1772: 509-523, 2007

27. Bandiera S, Rüberg S, Girard M, Cagnard N, Hanein S, Chrétien D, Munnich A, Lyonnet S and Henrion-Caude A: Nuclear outsourcing of RNA interference components to human mitochondria. PLoS One 6: e20746, 2011.

28. Stefano GB and Kream RM: Mitochondrial DNA heteroplasmy in human health and disease. Biomed Rep 4: 259-262, 2016.

29. Hudson G, Gomez-Duran A, Wilson IJ and Chinnery PF: Recent mitochondrial DNA mutations increase the risk of developing common late-onset human diseases. PLoS Genet 10: e1004369, 2014.

30. Hudson G, Carelli V, Spruijt L, Gerards M, Mowbray C, Achilli A, Pyle A, Elson J, Howell N, La Morgia C, et al: Clinical expression of Leber hereditary optic neuropathy is affected by the mitochondrial DNA-haplogroup background. Am J Hum Genet 81: 228-233, 2007.

31. Soini HK, Moilanen JS, Vilmi-Kerälä T, Finnilä S and Majamaa K: Mitochondrial DNA variant $\mathrm{m} .15218 \mathrm{~A}>\mathrm{G}$ in Finnish epilepsy patients who have maternal relatives with epilepsy, sensorineural hearing impairment or diabetes mellitus. BMC Med Genet 14: 73, 2013.

32. Fragaki K, Procaccio V, Bannwarth S, Serre V, O'Hearn S, Potluri P, Augé G, Casagrande F, Caruba C, Lambert JC, et al: A neonatal polyvisceral failure linked to a de novo homoplasmic mu-tation in the mitochondrially encoded cytochrome $b$ gene. Mitochondrion 9: 346-352, 2009.

33. Ghezzi D, Marelli C, Achilli A, Goldwurm S, Pezzoli G, Barone P, Pellecchia MT, Stanzione P, Brusa L, Bentivoglio AR, et al: Mitochondrial DNA haplogroup $\mathrm{K}$ is associated with a lower risk of Parkinson's disease in Italians. Eur J Hum Genet 13: 748-752, 2005.

34. Huerta C, Castro MG, Coto E, Blázquez M, Ribacoba R, Guisasola LM, Salvador C, Martínez C, Lahoz CH and Alvarez V: Mitochondrial DNA polymorphisms and risk of Parkinson's disease in Spanish population. J Neurol Sci 236: 49-54, 2005.

35. Galmiche L, Serre V, Beinat M, Assouline Z, Lebre AS, Chretien D, Nietschke P, Benes V, Boddaert N, Sidi D, et al: Exome sequencing identifies MRPL3 mutation in mitochondrial cardio-myopathy. Hum Mutat 32: 1225-1231, 2011.

36. Götz A, Tyynismaa H, Euro L, Ellonen P, Hyötyläinen T, Ojala T, Hämäläinen RH, Tommiska J, Raivio T, Oresic M, et al: Exome sequencing identifies mitochondrial alanyl-tRNA synthetase mutations in infantile mitochondrial cardiomyopathy. Am J Hum Genet 88: 635-642, 2011.

37. Bayat V, Thiffault I, Jaiswal M, Tétreault M, Donti T, Sasarman F, Bernard G, Demers-Lamarche J, Dicaire MJ, Mathieu J, et al: Mutations in the mitochondrial methionyl-tRNA synthe-tase cause a neurodegenerative phenotype in flies and a recessive ataxia (ARSAL) in humans. PLoS Biol 10: e1001288, 2012.

38. Elo JM, Yadavalli SS, Euro L, Isohanni P, Götz A, Carroll CJ, Valanne L, AlkurayaFS, Uusimaa J, Paetau A, et al: Mitochondrial phenylalanyl-tRNA synthetase mutations underlie fatal infantile Alpers encephalopathy. Hum Mol Genet 21: 4521-4529, 2012.
39. Haack TB, Kopajtich R, Freisinger P, Wieland T, Rorbach J, Nicholls TJ,Baruffini E, Walther A,Danhauser K,Zimmermann FA, et al: ELAC2 mutations cause a mitochondrial RNA processing defect associated with hypertrophic cardiomyopathy. Am J Hum Genet 93: 211-223, 2013

40. Soiferman D, Ayalon O, Weissman S and Saada A: The effect of small molecules on nuclear-encoded translation diseases. Biochimie 100: 184-191, 2014.

41. Powell CA, Nicholls TJ and Minczuk M: Nuclear-encoded factors involved in post-transcriptional processing and modification of mitochondrial tRNAs in human disease. Front Genet 6: 79, 2015.

42. Takakubo F, Cartwright P, Hoogenraad N, Thorburn DR, Collins F, Lithoow T and Dahl HH: An amino acid substitution in the pyruvate dehydrogenase E1 alpha gene, affecting mitochondrial import of the precursor protein. Am J Hum Genet 57: 772-780, 1995

43. Weraarpachai W, Sasarman F, Nishimura T, Antonicka H, Auré K, Rötig A, Lombès A and Shoubridge EA: Mutations in C12orf62, a factor that couples COX I synthesis with cytochrome $c$ oxidase assembly, cause fatal neonatal lactic acidosis. Am J Hum Genet 90: 142-151, 2012.

44. Larman TC, DePalma SR, Hadjipanayis AG, Protopopov A, Zhang J, Gabriel SB, Chin L, Seidman CE, Kucherlapati R and Seidman JG; Cancer Genome Atlas Research Network: Spectrum of somatic mitochondrial mutations in five cancers. Proc Natl Acad Sci USA 109: 14087-14091, 2012.

45. Kenny TC, Hart P, Ragazzi M, Sersinghe M, Chipuk J, Sagar MA, Eliceiri KW, LaFramboise T, Grandhi S, Santos J, et al: Selected mitochondrial DNA landscapes activate the SIRT3 axis of the UPRmt to promote metastasis. Oncogene 36: 4393-4404, 2017.

46. Ahn EH, Hirohata K, Kohrn BF, Fox EJ, Chang CC and Loeb LA: Detection of ultrarare mi-tochondrial mutations in breast stem cells by duplex sequencing. PLoS One 10: e0136216, 2015.

47. Polyak K, Li Y, Zhu H, Lengauer C, Willson JK, Markowitz SD, Trush MA, Kinzler KW and Vogelstein B: Somatic mutations of the mitochondrial genome in human colorectal tumours. Nat Genet 20: 291-293, 1998.

48. Yadav $\mathrm{N}$ and Chandra D: Mitochondrial DNA mutations and breast tumorigenesis. Biochim Bi-ophys Acta 1836: 336-344, 2013.

49. Pedersen PL, Mathupala S, Rempel A, Geschwind JF and Ko YH: Mitochondrial bound type II hexokinase: A key player in the growth and survival of many cancers and an ideal prospect for ther-apeutic intervention. Biochim Biophys Acta 1555: 14-20, 2002.

50. Brandon M, Baldi P and Wallace DC: Mitochondrial mutations in cancer. Oncogene 25: 4647-4662, 2006.

51. Kirches E: Mitochondrial and nuclear genes of mitochondrial components in cancer. Curr Genomics 10: 281-293, 2009.

52. Kenny TC and Germain D: mtDNA, metastasis, and the mitochondrial unfolded protein response (UPRmt). Front Cell Dev Biol 5: 37, 2017.

53. Habano W, Sugai T, Yoshida T and Nakamura S: Mitochondrial gene mutation, but not large-scale deletion, is a feature of colorectal carcinomas with mitochondrial microsatellite instability. Int J Cancer 83: 625-629, 1999.

54. Petros JA, Baumann AK, Ruiz-Pesini E, Amin MB, Sun CQ, Hall J, Lim S, Issa MM, Flanders WD, Hosseini SH, et al: mtDNA mutations increase tumorigenicity in prostate cancer. Proc Natl Acad Sci USA 102: 719-724, 2005

55. Yu M, Shi Y, Zhang F, Zhou Y, Yang Y, Wei X, Zhang L and Niu R: Sequence variations of mitochondrial DNA D-loop region are highly frequent events in familial breast cancer. J Biomed Sci 15: 535-543, 2008

56. Liu VW, Wang Y, Yang HJ, Tsang PCK, Ng TY, Wong LC, Nagley P and Ngan HY: Mito-chondrial DNA variant $16189 \mathrm{~T}>C$ is associated with susceptibility to endometrial cancer. Hum Mutat 22: 173-174, 2003.

57. Canter JA, Kallianpur AR, Parl FF and Millikan RC: Mitochondrial DNA G10398A polymorphism and invasive breast cancer in African-American women. Cancer Res 65: 8028-8033, 2005

58. Zhang J, Asin-Cayuela J, Fish J, Michikawa Y, Bonafe M, Olivieri F, Passarino G, De Benedictis G, Franceschi C and Attardi G: Strikingly higher frequency in centenarians and twins of mtDNA mutation causing remodeling of replication origin in leukocytes. Proc Natl Acad Sci USA 100: 1116-1121, 2003.

59. Liou CW, Lin TK, Chen JB, Tiao MM, Weng SW, Chen SD, Chuang YC, Chuang JH and Wang PW: Association between a common mitochondrial DNA D-loop polycytosine variant and alteration of mitochondrial copy number in human peripheral blood cells. J Med Genet 47: 723-728, 2010. 
60. Peng TI, Yu PR, Chen JY, Wang HL, Wu HY, Wei YH and Jou MJ: Visualizing common deletion of mitochondrial DNA-augmented mitochondrial reactive oxygen species generation and apoptosis upon oxidative stress. Biochim Biophys Acta 1762: 241-255, 2006.

61. Su X, Wang W, Ruan G, Liang M, Zheng J, Chen Y, Wu H, Fahey TJ III, Guan M and Teng L: A comprehensive characterization of mitochondrial genome in papillary thyroid cancer. Int J Mol Sci 17: 1594, 2016.

62. Wang Y, Liu VW, Xue WC, Tsang PC, Cheung AN and Ngan HY: The increase of mitochondrial DNA content in endometrial adenocarcinoma cells: A quantitative study using laser-captured microdissected tissues. Gynecol Oncol 98: 104-110, 2005.

63. SinghB,Owens KM,BajpaiP,DesoukiMM,SrinivasasainagendraV, Tiwari HK and Singh KK: Mitochondrial DNA polymerase POLG1 disease mutations and germline variants promote tumorigenic properties. PLoS One 10: e0139846, 2015.

64. Reznik E, Miller ML, Şenbabaoğlu Y, Riaz N, Sarungbam J, Tickoo SK, Al-Ahmadie HA, Lee W, Seshan VE, Hakimi AA, et al: Mitochondrial DNA copy number variation across human cancers. eLife 5: e10769, 2016.

65. Booker LM, Habermacher GM, Jessie BC, Sun QC, Baumann AK, Amin M, Lim SD, Fernan-dez-Golarz C, Lyles RH, Brown MD, et al: North American white mitochondrial haplogroups in prostate and renal cancer. J Urol 175: 468-473, 2006.

66. Fang H, Shen L, Chen T, He J, Ding Z, Wei J, Qu J, Chen G, Lu J and Bai Y: Cancer type-specific modulation of mitochondrial haplogroups in breast, colorectal and thyroid cancer. BMC Cancer 10: 421, 2010.

67. Hu SP, Du JP, Li DR and Yao YG: Mitochondrial DNA haplogroup confers genetic susceptibility to nasopharyngeal carcinoma in Chaoshanese from Guangdong, China. PLoS One 9: e87795, 2014.

68. Li Y, Beckman KB, Caberto C, Kazma R, Lum-Jones A, Haiman CA, Le Marchand L, Stram DO, Saxena R and Cheng I: Association of genes, pathways, and haplogroups of the mitochondrial genome with the risk of colorectal cancer: The multiethnic Cohort. PLoS One 10: e0136796, 2015.

69. Jiang J, Zhao JH, Wang XL, Di JI, Liu ZB, Li GY, Wang MZ, Li Y, Chen R and Ge RL: Analysis of mitochondrial DNA in Tibetan gastric cancer patients at high altitude. Mol Clin Oncol 3: $875-879,2015$

70. Poynter JN, Richardson M, Langer E, Hooten AJ, Roesler M, Hirsch B, Nguyen PL, Cioc A, Warlick E and Ross JA: Association between mitochondrial DNA haplogroup and myelodysplastic syndromes. Genes Chromosomes Cancer 55: 688-693, 2016.

71. Singh KK and Kulawiec M: Mitochondrial DNA polymorphism and risk of cancer. Methods Mol Biol 471: 291-303, 2009.

72. Yacoub HA, Mahmoud WM,El-Baz HA,Eid OM,El-Fayoumi RI Mahmoud MM,Harakeh S and Abuzinadah OH: New haplotypes of the ATP synthase subunit 6 gene of mitochondrial DNA are associated with acute lymphoblastic leukemia in Saudi Arabia. Asian Pac J Cancer Prev 15: 10433-10438, 2014.

73. Cano D, Gomez CF, Ospina N, Cajigas JA, Groot H, Andrade RE and Torres MM: Mitochon-drial DNA haplogroups and susceptibility to prostate cancer in a colombian population. ISRN Oncol 2014: 530675, 2014.

74. Yu FY, Xu Q, Wu DD, Lau AT and Xu YM: The Prognostic and Clinicopathological roles of Sirtuin-3 in various cancers. PLoS One 11: e0159801, 2016.

75. Czarnecka AM, Krawczyk T, Plak K, Klemba A, Zdrozny M, Arnold RS, Kofler B, Golik P, Szybinska A, Lubinski J, et al: Mitochondrial genotype and breast cancer predisposition. Oncol Rep 24: 1521-1534, 2010.

76. Verma M, Naviaux RK, Tanaka M, Kumar D, Franceschi C and Singh KK: Meeting report: Mitochondrial DNA and cancer epidemiology. Cancer Res 67: 437-439, 2007.

77. van Gisbergen MW, Voets AM, Starmans MH, de Coo IF, Yadak R, Hoffmann RF, Boutros PC, Smeets HJ, Dubois L and Lambin P: How do changes in the mtDNA and mitochondrial dysfunction influence cancer and cancer therapy? Challenges, opportunities and models. Mutat Res Rev Mutat Res 764: 16-30, 2015.

78. Parker SJ and Metallo CM: Metabolic consequences of oncogenic IDH mutations. Pharmacol Ther 152: 54-62, 2015.

79. Reitman ZJ, Jin G, Karoly ED, Spasojevic I, Yang J, Kinzler KW, He Y, Bigner DD, Vogelstein B and Yan H: Profiling the effects of isocitrate dehydrogenase 1 and 2 mutations on the cellu-lar metabolome. Proc Natl Acad Sci USA 108: 3270-3275, 2011.

80. Burnichon N, Brière JJ, Libé R, Vescovo L, Rivière J, Tissier F Jouanno E, Jeunemaitre X, Bénit P, Tzagoloff A, et al: SDHA is a tumor suppressor gene causing paraganglioma. Hum Mol Genet 19: 3011-3020, 2010
81. Zhang B, Wang J, Huang Z, Wei P, Liu Y, Hao J, Zhao L, Zhang F, Tu Y and Wei T: Aberrantly upregulated TRAP1 is required for tumorigenesis of breast cancer. Oncotarget 6: 44495-44508, 2015.

82.Lin YF, Schulz AM, Pellegrino MW, Lu Y, Shaham S and Haynes CM: Maintenance and propagation of a deleterious mitochondrial genome by the mitochondrial unfolded protein response. Nature 533: 416-419, 2016.

83. McMahon $\mathrm{S}$ and LaFramboise T: Mutational patterns in the breast cancer mitochondrial genome, with clinical correlates. Carcinogenesis 35: 1046-1054, 2014.

84. Yu Y, Lv F, Lin H, Qian G, Jiang YS, Pang LX, Wang YP, Wang XF, Kang YM, Li CB, et al: Mitochondrial ND3 G10398A mutation: A biomarker for breast cancer. Genet Mol Res 14: 17426-17431, 2015.

85. Bai RK, Leal SM, Covarrubias D, Liu A and Wong LJ: Mitochondrial genetic background modifies breast cancer risk. Cancer Res 67: 4687-4694, 2007.

86.Zhu W, Qin W, Bradley P, Wessel A, Puckett CL and Sauter ER: Mitochondrial DNA mutations in breast cancer tissue and in matched nipple aspirate fluid. Carcinogenesis 26: 145-152, 2005.

87. Wang Y, Liu VW, Tsang PC, Chiu PM, Cheung AN, Khoo US, Nagley P and Ngan HY: Microsatellite instability in mitochondrial genome of common female cancers. Int J Gynecol Cancer 16 (Suppl 1): 259-266, 2006

88. Bianchi MS, Bianchi NO and Bailliet G: Mitochondrial DNA mutations in normal and tumor tissues from breast cancer patients. Cytogenet Cell Genet 71: 99-103, 1995.

89. Shakhssalim N, Houshmand M, Kamalidehghan B, Faraji A, Sarhangnejad R, Dadgar S, Mobaraki M, Rosli R and Sanati MH: The mitochondrial C16069T polymorphism, not mitochondrial D310 (D-loop) mononucleotide sequence variations, is associated with bladder cancer. Cancer Cell Int 13: 120, 2013.

90. Tipirisetti NR, Govatati S, Pullari P, Malempati S, Thupurani MK, Perugu S, Guruvaiah P, Rao KL, Digumarti RR, Nallanchakravarthula $\mathrm{V}$, et al: Mitochondrial control region alterations and breast cancer risk: A study in South Indian population. PLoS One 9: e85363, 2014.

91. Fendt L, Niederstätter H, Huber G, Zelger B, Dünser M, Seifarth C, Röck A, Schäfer G, Klock-er H and Parson W: Accumulation of mutations over the entire mitochondrial genome of breast cancer cells obtained by tissue microdissection. Breast Cancer Res Treat 128: 327-336, 2011.

92. Ebner S, Lang R, Mueller EE, Eder W, Oeller M, Moser A, Koller J, Paulweber B, Mayr JA, Sperl W, et al: Mitochondrial haplogroups, control region polymorphisms and malignant melanoma: A study in middle European Caucasians. PLoS One 6: e27192, 2011.

93. Wang CY, Wang HW, Yao YG, Kong QP and Zhang YP: Somatic mutations of mitochondrial genome in early stage breast cancer. Int J Cancer 121: 1253-1256, 2007.

94. Czarnecka AM, Klemba A, Krawczyk T, Zdrozny M, Arnold RS, Bartnik E and Petros JA: Mitochondrial NADH-dehydrogenase polymorphisms as sporadic breast cancer risk factor. Oncol Rep 23: 531-535, 2010.

95. Weigl S, Paradiso A and Tommasi S: Mitochondria and familial predisposition to breast cancer. Curr Genomics 14: 195-203, 2013.

96. Li L, Chen L, Li J, Zhang W, Liao Y, Chen J and Sun Z Correlational study on mitochondrial DNA mutations as potential risk factors in breast cancer. Oncotarget 7: 31270$31283,2016$.

97. Rohan TE, Wong LJ, Wang T, Haines J and Kabat GC: Do alterations in mitochondrial DNA play a role in breast carcinogenesis? J Oncol 2010: 604304, 2010.

98. Covarrubias D, Bai RK, Wong LJ and Leal SM: Mitochondrial DNA variant interactions modify breast cancer risk. J Hum Genet 53: 924-928, 2008 .

99. Darvishi K, Sharma S, Bhat AK, Rai E and Bamezai RN: Mitochondrial DNA G10398A polymorphism imparts maternal Haplogroup $\mathrm{N}$ a risk for breast and esophageal cancer. Cancer Lett 249: 249-255, 2007

100. Tengku Baharudin N, Jaafar H and Zainuddin Z: Association of mitochondrial DNA 10398 polymorphism in invasive breas cancer in malay population of peninsular malaysia. Malays J Med Sci 19: 36-42, 2012

101. Tan DJ, Bai RK and Wong LJ: Comprehensive scanning of somatic mitochondrial DNA mutations in breast cancer. Cancer Res 62: 972-976, 2002 
102. Gallardo ME, Moreno-Loshuertos R, López C, Casqueiro M, Silva J, Bonilla F, Rodríguez de Córdoba S and Enríquez JA: m.6267G $>$ A: a recurrent mutation in the human mitochondrial DNA that reduces cytochrome $c$ oxidase activity and is associated with tumors. Hum Mutat 27: 575-582, 2006.

103. Aral C, Kaya H, Ataizi-Celikel C, Akkiprik M, Sonmez O, Gulluoglu BM and Ozer A: A novel approach for rapid screening of mitochondrial D310 polymorphism. BMC Cancer 6: 21, 2006.

104. Ma Y, Bai RK, Trieu R and Wong LJ: Mitochondrial dysfunction in human breast cancer cells and their transmitochondrial cybrids. Biochim Biophys Acta 1797: 29-37, 2010.

105. Santos GC Jr, Góes AC, Vitto H, Moreira CC, Avvad E, Rumjanek FD and Moura Gallo CV: Genomic instability at the $13 q 31$ locus and somatic mtDNA mutation in the D-loop site correlate with tumor aggressiveness in sporadic Brazilian breast cancer cases. Clinics (São Paulo) 67: 1181-1190, 2012.

106.Xu C, Tran-Thanh D, Ma C, May K, Jung J, Vecchiarelli J and Done SJ: Mitochondrial D310 mutations in the early development of breast cancer. Br J Cancer 106: 1506-1511, 2012.

107. Parrella P, Xiao Y, Fliss M, Sanchez-Cespedes M, Mazzarelli P, Rinaldi M, Nicol T, Gabriel-son E, Cuomo C, Cohen D, et al: Detection of mitochondrial DNA mutations in primary breast can-cer and fine-needle aspirates. Cancer Res 61: 7623-7626, 2001.

108. Alhomidi MA, Vedicherla B, Movva S, Rao PK, Ahuja YR and Hasan Q: Mitochondrial D310 instability in Asian Indian breast cancer patients. Tumour Biol 34: 2427-2432, 2013.

109.Lott MT, Leipzig JN, Derbeneva O, Xie HM, Chalkia D, Sarmady M, Procaccio V and Wallace DC: mtDNA variation and analysis using mitomap and mitomaster. Curr Protoc Bioinformatics 44: 1.23.1-1.23.26, 2013.

110. Payne BA, Wilson IJ, Yu-Wai-Man P, Coxhead J, Deehan D, Horvath R, Taylor RW, Samuels DC, Santibanez-Koref M and Chinnery PF: Universal heteroplasmy of human mitochondrial DNA. Hum Mol Genet 22: 384-390, 2013.

111. Weerts MJ, Sieuwerts AM, Smid M, Look MP, Foekens JA, Sleijfer S and Martens JW: Mitochondrial DNA content in breast cancer: Impact on in vitro and in vivo phenotype and patient prognosis. Oncotarget 7: 29166-29176, 2016.

112. Mueller EE, Brunner SM, Mayr JA, Stanger O, Sperl W and Kofler B: Functional differences between mitochondrial haplogroup $\mathrm{T}$ and haplogroup $\mathrm{H}$ in HEK293 cybrid cells. PLoS One 7: e52367, 2012.

113. Tommasi S, Favia P, Weigl S, Bianco A, Pilato B, Russo L, Paradiso A and Petruzzella V: Mitochondrial DNA variants and risk of familial breast cancer: An exploratory study. Int J Oncol 44: 1691-1698, 2014.

114. Blein S, Bardel C, Danjean V, McGuffog L, Healey S, Barrowdale D, Lee A, Dennis J, Kuchenbaecker KB, Soucy P, et al; Breast Cancer Family Registry; EMBRACE; GEMO Study Col-laborators; HEBON: An original phylogenetic approach identified mitochondrial haplogroup T1a1 as inversely associated with breast cancer risk in BRCA2 mutation carriers. Breast Cancer Res 17: 61, 2015.

115. Rao R, Rivers A, Rahimi A, Wooldridge R, Rao M, Leitch M, Euhus D and Haley BB: Genetic ancestry using mitochondrial DNA in patients with triple-negative breast cancer (GAMiT study). Cancer 123: 107-113, 2017.

116. Mosquera-Miguel A, Alvarez-Iglesias V, Carracedo A, Salas A, Vega A, Carracedo A, Milne R, de León AC,Benitez J, Carracedo A, et al: Is mitochondrial DNA variation associated with sporadic breast cancer risk? Cancer Res 68: 623-625, author reply 624, 2008.
117. van Oven M and Kayser M: Updated comprehensive phylogenetic tree of global human mitochondrial DNA variation. Hum Mutat 30: E386-E394, 2009.

118. Salas A, García-Magariños M, Logan I and Bandelt HJ: The saga of the many studies wrongly associating mitochondrial DNA with breast cancer. BMC Cancer 14: 659, 2014.

119. Walsh T, Casadei S, Coats KH, Swisher E, Stray SM, Higgins J, Roach KC, Mandell J, Lee MK, Ciernikova S, et al: Spectrum of mutations in BRCA1, BRCA2, CHEK2, and TP53 in families at high risk of breast cancer. JAMA 295: 1379-1388, 2006.

120. Hossein R and Houshmand M: Diagnostic algorithm for identification of individuals with hereditary predisposition to breast cancer. Lik Sprava 1-2: 103-108, 2008.

121. Jandova J, Janda J and Sligh JE: Changes in mitochondrial DNA alter expression of nuclear encoded genes associated with tumorigenesis. Exp Cell Res 318: 2215-2225, 2012.

122.Zhang Q, Liang Z, Gao Y, Teng M and Niu L: Differentially expressed mitochondrial genes in breast cancer cells: Potential new targets for anti-cancer therapies. Gene 596: 45-52, 2017.

123. Lin CS, Chang SC, Ou LH, Chen CM, Hsieh SS, Chung YP, King KL, Lin SL and Wei YH: Mitochondrial DNA alterations correlate with the pathological status and the immunological ER, PR, HER-2/neu, p53 and Ki-67 expression in breast invasive ductal carcinoma. Oncol Rep 33: 2924-2934, 2015.

124. Blein S, Barjhoux L, Damiola F, Dondon MG, Eon-Marchais S, Marcou M, Caron O, Lortholary A, Buecher B, Vennin P, et al; GENESIS investigators: Targeted sequencing of the mitochondrial genome of women at high risk of breast cancer without detectable mutations in BRCA1/2. PLoS One 10: e0136192, 2015.

125. Hsu CW, Yin PH, Lee HC, Chi CW and Tseng LM: Mitochondrial DNA content as a potential marker to predict response to anthracycline in breast cancer patients. Breast J 16: 264-270, 2010.

126. Farnie G, Sotgia F and Lisanti MP: High mitochondrial mass identifies a sub-population of stem-like cancer cells that are chemo-resistant. Oncotarget 6: 30472-30486, 2015.

127. Ferreri AJ, Ponzoni M, Guidoboni M, Resti AG, Politi LS, Cortelazzo S, Demeter J, Zallio F, Palmas A, Muti G, et al: Bacteria-eradicating therapy with doxycycline in ocular adnexal MALT lymphoma: A multicenter prospective trial. J Natl Cancer Inst 98: 1375-1382, 2006.

128. Lamb R, Harrison H, Hulit J, Smith DL, Lisanti MP and Sotgia F: Mitochondria as new therapeutic targets for eradicating cancer stem cells: Quantitative proteomics and functional validation via MCT1/2 inhibition. Oncotarget 5: 11029-11037, 2014.

129. Ferreri AJ, Ponzoni M, Guidoboni M, De Conciliis C, Resti AG, Mazzi B, Lettini AA, De-meter J, Dell'Oro S, Doglioni C, et al: Regression of ocular adnexal lymphoma after Chlamydia psittaci-eradicating antibiotic therapy. J Clin Oncol 23: 50675073, 2005.

130. Teixeira FK, Sanchez CG, Hurd TR, Seifert JRK, Czech B, Preall JB, Hannon GJ and Lehmann R: ATP synthase promotes germ cell differentiation independent of oxidative phosphorylation. Nat Cell Biol 17: 689-696, 2015. 